\title{
Pengaruh Kompres Serai Hangat terhadap Intensitas Nyeri Arthrtitis Rheumatoid pada Lanjut Usia di Panti Sosial Tresna Werdha Budi Luhur
}

\author{
Nurfitriani $^{1}$, Tina Yuli Fatmawati ${ }^{2}$ \\ ${ }^{1,2}$ Program Studi D III Keperawatan STIKes Baiturrahim Jambi \\ Email : nurfitriani1173@gmail.com
}

Submitted :06/04/2020

Accepted: 20/04/2020

Published: 07/09/2020

\begin{abstract}
Rheumatoid arthritis or often called rheumatism is a disorder that continues to undermine health and destroy the quality of human life, several types of rheumatic disorders have been identified earlier so that the number of sufferers will increase as more people develop rheumatism, so the need for treatment will increase as well. Data obtained at Tresna Werdha Social Home, out of 70 elderly people, 43 of them suffered from rheumatoid arthritis. The purpose of this study was to determine the effect of Warm Lemongrass Compress Against Pain Intensity in Rheumatoid Arthritis in Elderly People at Tresna Werdha Social Home Budi Luhur Jambi. The research design used was a Pre-Experiment design with One Group Pre-Post Test Design. The study was conducted at the Budi Luhur Nursing Home in Jambi. The sampling method was carried out using purposive sampling, with 15 respondents consisting of the Serai compress. Analysis of the data will be used univariate analysis and bivariate analysis with the t-test Dependent. The results were obtained. by pain intensity in elderly Rheumatoid Arthrtitis before the average treatment 6.90 and after the pain is reduced to an average of 4.13. There is an effect of giving warm lemongrass compresses on decreasing the intensity of Rheumatoid Arthritis pain in the elderly at Tresna Werdha Social Home in Jambi City with p-value $=0,000$. It is recommended to the room nurse or the person in charge of the room to be able to try to implement or demonstrate of warm lemongrass compresses so as to reduce the intensity of pain in the elderly.
\end{abstract}

Keywords: elderly, pain intensity, rheumatoid arthritis, warm lemongrass compress

\begin{abstract}
Abstrak
Arthrtitis Rheumatoid atau sering disebut Rematik merupakan gangguan yang terus-menerus menggerogoti kesehatan dan menghancurkan kualitas hidup manusia, beberapa jenis gangguan rematik ini telah berhasil dikenali lebih dini sehingga jumlah penderita seakan - akan meningkat dan kebutuhan akan perawatannyapun semakin meningkat pula. Data yang diperoleh di Panti Sosial Tresna Werdha, dari 70 lansia , 43 diantaranya menderita Arthrtitis Rheumatoid. Tujuan dari penelitian ini untuk mengetahui Pengaruh Kompres Serai Hangat Terhadap Intensitas Nyeri Arthrtitis Rheumatoid Pada Lansia Di Panti Sosial Tresna Werdha Budi Luhur Jambi. Rancangan penelitian menggunakan rancangan Pre - Eksperiment dengan One Group Pre - Post Tes Design. Penelitian ini telah dilakukan di Panti Werdha Budi Luhur Jambi. Pengambilan sampel secara purposive sampling berjumlah 15 responden. Analisa data yang akan digunakan analisis univariat dan analisis bivariat dengan uji t- test Dependent. Hasil penelitian diperoleh intensitas nyeri Arthrtitis Rheumatoid lansia sebelum tindakan rata rata 6,90 dan setelah dilakukan tindakan nyeri berkurang menjadi rata rata 4,13. Ada pengaruh pemberian kompres serai hangat terhadap penurunan intensitas nyeri Arthrtitis Rheumatoid pada lansia di Panti Sosial Tresna Werdha Kota Jambi dengan nilai $p$-value $=0,000$. Disarankan kepada perawat ruangan atau penanggung jawab ruangan agar menerapkan atau melakukan intervensi kompres serai hangat sehingga dapat menurunkan intensitas nyeri pada lansia.
\end{abstract}

Kata Kunci: arthritis rematoid, intensitas nyeri, kompres serai hangat, lanjut usia 


\section{PENDAHULUAN}

Menua atau menjadi tua adalah suatu proses dimana menghilangnya secara perlahan-lahan kemampuan jaringan untuk memperbaiki diri atau mengganti dan mempertahankan fungsi normalnya sehingga tidak dapat bertahan terhadap infeksi dan memperbaiki kerusakan yang diderita (Constantanides, 1994 didalam Bandiyah, 2009). Lansia adalah keadaan yang ditandai oleh kegagalan dari seseorang mempertahankan keseimbangan terhadap kondisi stress fisiologik. Perubahan yang terjadi pada lansia secara fisik salah satunya kehilangan elastisitas dan fleksibilitas persendian, dan tulang mulai keropos(Hutapea,2005). Masalah kesehatan lansia dengan nyeri sendi di Indonesia yang terjadi pada umur 55-64 tahun (15,5\%), umur 65-74 tahun $(18,6 \%)$ dan umur 75 tahun keatas $(18,9 \%)$. Sedangkan Prevalensi penyakit sendi berdasar diagnosis pada penduduk umur $\geq 15$ tahun menurut provinsi 2018 bahwa yang tertinggi di Aceh (13,3\%), diikuti Bengkulu $(12,7 \%)$, Bali (11\%) dan Papua (11\%). Sedangkan pada provinsi Jambi diagnosis penduduk umur $\geq 15$ tahun $(8,9 \%)$ (Riskesdas, 2018).

Berdasarkan data morbiditas pasien rawat inap rumah sakit provinsi Jambi klasifikasi umur $>44-64$ tahun dan $>64$ tahun yang menderita rematik berjumlah 292 jiwa (Dinas Kesehatan Provinsi Jambi, 2017). Menurut Dinas Kesehatan Kota Jambi bahwa dari berbagai pelayanan puskesmas yang ada di kota Jambi jumlah total penduduk yang menderita rematik baik dari jenis artritis (3371 jiwa), gout (2740 jiwa), idiopatik gout (517 jiwa), poly artritis nodosa (384 jiwa), dan rhematoid tak spesifik (6116 jiwa) (Dinas Kesehatan Kota Jambi, 2017).

Provinsi Jambi merupakan salah satu provinsi di Indonesia. Menurut profil kesehatan Indonesia 2017,bahwa di provinsi Jambi jumlah penduduk usia non produktif dengan umur 65 keatas didapatkan total jumlah keseluruhan yakni 146.305 jiwa lansia yang dimana laki-laki sebanyak 71.530 orang dan 74.775 orang berjenis kelamin perempuan (Kemenkes RI, 2017). Menurut data pencatatan dan pelaporan kesehatan lansia di dinas kesehatan kota Jambi menunjukkan jumlah dalam sasaran lansia (PUSDATIN) pada kategori umur 45-59 baik laki-laki maupun perempuan berjumlah 102.572 jiwa, umur 60-69 tahun berjumlah 40.070 jiwa dan kategori umur $>70$ tahun berjumlah 14.197 jiwa (Dinkes Kota Jambi, 2017).

Di Indonesia jumlah lanjut usia pada tahun 2006 sebanyak 19 juta jiwa, diperkirakan pada tahun 2010 akan mencapai 23,9 juta jiwa, dan prakiraan pada tahun 2020 jumlah lanjut usia akan mencapai 28,8 juta jiwa (Dermawan, 2012). Pada umumya lanjut usia akan mengalami berbagai macam penyakit, diantaranya yaitu Artritis rheumatoid 49,0\%, Hipertensi (+CVP) 15,2\% Bronchitis 7,3\%, DM 3,3\%, cedera 2,5\%, Stroke/Paralisis 2,1\%, TBC 1,8\%, Fraktur Tulang 1,0\%, Kanker 0,7\%, masalah kesehatan yang mempengaruhi ADL 29,1\% (Nugroho, 2000).

Data tahun 2004 menunjukkan bahwa penderita AtritisRheumatiddi Indonesia mencapai 2 jutaorang, jumlah yang kecil dibanding penderita Negara India. Data macam penyakit yang dikumpulkan dari Survey Kesehatan Rumah Tangga (SKRT) pada usia lebih dari 50 tahun, penyakit muskuloskeletal sebanyak 14,05\%, 100 pasien berada pada urutan kedua (Suryono, 2001 :251).

Arthrtitis Rheumatoid merupakan suatu penyakit autoimun dimana pada lapisan persendian mengalami peradangan sehingga menyebabkan rasa nyeri, kekakuan, kelemahan, kemerahan, bengkak dan panas, penyakit ini terjadi antara umur 20-50 tahun (Khitchen,2011). Arthritis rheumathoid merupakan penyakit inflamasi sistemik kronis yang menyerang beberapa sendi, sinoviom adalah bagian yang terjadi 
pada proses peradangan yang menyebabkan kerusakan pada tulang sendi (Sudoyo,2005) .Faktor penyebab penyakit ini belum diketahui secara pasti, namun faktor genetik seperti produk kompleks Histokompatibilitas utama kelas II Human Leukosit Antigen-DR subregion(HLA-DR) dan beberapa faktor lingkungan di duga berperan dalam timbulnya penyakit ini (Sudoyo, dkk, 2007 dalam Wiarto, 2017). Menurut Sudoyo, 2007, artritis rhematoid diduga disebabkan oleh faktor autoimun dan infeksi, autoimun ini bereaksi terhadap kolagen tipe 11 dari tulang rawan sendi penderita dengan beberapa faktor resiko yang diketahui berhubungan dengan arthritis rhematoid, antara lain: a) usia lebih dari 40 tahun; b) kgemukan dan gangguan metabolik; c) Cidera sensitif yang berulang; d) kepadatan tulang yang berkurang dan e) beban sendi yang terlalu berat.

Artritis rheumatoid atau yang sering disebut rematik sering menunjukkan gejala gejala berikut seperti : a) Nyeri sendi, terutama pada saat bergerak; b) umumnya terjadi sendi penopang beban tubuh, seperti panggul, tulang belakang dan lutut; c) terjadi kemerahan, inflamasi nyeri sendi dan dapat terjadi deformitas; d) rasa sakit bertambah hebat pada sendi pinggul, utut dan jari jari serat pada saat perpindahan posisi bisa terdengar suara cracking( Priyatno, dalam Wuarto (wiarto, 2017).

Manajemen keperawatan nonfarmakologi dapat menurunkan nyeri dengan risiko yang rendah bagi pasien dan tidak membutuhkan biaya yang besar. Meskipun tindakan tersebut bukan merupakan pengganti untuk obat-obatan, tindakan tersebut mungkin dapat mempersingkat episode nyeri (Smeltzer, 2001).

Salah satu tindakan untuk menghilangkan nyeri secara nonfarmakologi yaitu dengan menghangatkan persendian yang sakit. Mekanisme metode ini sama dengan metode terapi pijat yang menggunakan terapi gate kontrol. Ada bermacam-macam cara pemanasan yaitu kompres hangat dengan handuk, dengan mendekatkan botol ke kedua sendi yang sakit dan bisa juga dengan berjemur di bawah sinar matahari. Penggunaan panas mempunyai keuntungan meningkatkan aliran darah ke suatu area dan kemungkinan dapat turut menurunkan nyeri, panas yang lembab dapat menghilangkan kekakuan pada pagi hari akibat artritis (Ceccio, 1990 dalam Potter, Perry, 2001). Salah satu intervensi non farmakologi yang dapat dilakukan perawat secara mandiri dalam menurunkan skala nyeri arthritis rhematoid, yaitu dengan melakukan kompres hangat Serai pada pasien untuk menurunkan skala nyeri artrhitis rheumatoid (Iskandar, 2008 ).

Serai adalah salah satu tanaman yang memiliki zat sebagai penghangat, anti radang dan dapat memperlancarkan aliran darah. Serai mengandung minyak atsiri yang memiliki efek tersebut (Wijayakusuma, 2007). Serai merupakan tanaman semak yang memiliki akar serabut besar dan berimpang pendek (Hidayat \& Napitupilu, 2015). Serai ini dapat menurunkan nyeri sendi, dengan pemberian minyak atsiri yang terkandung dalam serai tersebut (Hariana, 2015).

Selaras dengan penelitian yang dilakukan oleh Andriani (2016) menyatakan bahwa ada pengaruh pemberian kompres serai hangat pada nyeri Artritis Rheumatoid. Pada penelitian Hyulita (2013) serai juga terbukti menurunkan nyeri sendi, ini dibuktikan dengan penelitiannya dengan pemberian kompres serai hangat pada intensitas nyeri Artritis Rheumatoid pada lanjut usia. Hasil penelitian Handayani (2015), mengatakan bahwa serai termasuk tumbuhan yang dimanfaatkan sebagai tanaman obat untuk memberi kehangatan dengan cara mengoleskan minyak atsiri pada bagian yang diinginkan

Provinsi Jambi memiliki panti sosial atau panti jompo yang terletak di Paal Lima Kota Baru Jambi yang bernama Panti Sosial 
Tresna Werdha Budi Luhur Kota Jambi. Panti merupakan suatu institusi hunian bersama para lansia yang secara fisik atau kesehatan masih mandiri, akan tetapi (terutama) mempunyai keterbatasan di bidang sosial - ekonomi (Darmojo, 2015). Panti mempunyai tugas memberikan bimbingan dan pelayanan bagi lanjut usia terlantar agar dapat hidup secara wajar dalam kehidupan bermasyarakat (Kepmensos No.50/HUK/2004). Pada bulan Agustus 2018 jumlah lansia yang ada di Panti Werdha Budi Luhur Jambi adalah 70 orang , 43 lansia diantaranya menderita Arthitis Reumatoid (PSTW, 2018).

Survey yang dilakukan di Panti Sosial Tresna Werdha Budi Luhur Provinsi Jambi, pada 5 lansia putri, 2 diantaranya mengatakan sering mengeluh nyeri pada sendi tangan dan kaki terutama pada pagi hari. 3 lansia kadang-kadang tidak bisa menggerakkan kakinya karena nyeri yang timbul mendadak. Apabila nyeri dirasakan terus menerus lansia mengkonsumsi obatobatan yang didapatkan dari panti (Data panti, 2018).

Tujuan dari penelitian ini untuk mengetahui Pengaruh Kompres Serai Hangat Terhadap Intensitas Nyeri Arthrtitis Rheumatoid Pada Lanjut Usia Di Panti Sosial Tresna Werdha Budi Luhur Jambi ,

\section{METODE PENELITIAN}

Penelitian ini menggunakan rancangan Pre - Eksperiment dengan One Group Pre - Post Tes Design yaitu peneliti mencoba membuktikan pengaruh tindakan pada satu kelompok subjek. Kelompok subjek diobservasi sebelum pelaksanaan intervensi, kemudian diobservasi kembalii setelah intervensi untuk mengetahui akibat dari perlakuan (Sugiyono, 2008). Pada penelitian ini, sebelum dilakukan kompres Serai hangat (pre-test), skala nyeri lansia di ukur. Kemudian dilakukan kompres hangat Serai oleh peneliti selama 15 menit. Setelah itu diukur kembali (post-test) skala nyerinya. Kemudian dibandingkan antara nyeri pre-test dengan post-test.

Populasi dalam penelitian ini adalah seluruh lansia yang menderita Arthritis Reumatoid berjumlah 43 orang. Sampel pada penelitian ini diambil dari jumlah populasi yang tersedia yaitu sebanyak 15 orang dengan menggunakan tehnik purposive sampling dengan kriteria inklusinya yaitu: lansia yang menderita arthititis Reumatoid, tidak sedang mengkonsumsi obat golongan analgetik, bersedia menjadi responden dan dapat berkomunikasi dengan baik. Penelitian dilakukan pada bulan Desember 2018 s/d Januari 2019 di Panti Werdha Budi Luhur Jambi. Tehnik pengumpulan data menggunakan data primer dengan menggunakan kuisioner dan lembar observasi sebelum dan sesudah melakukan tindakan kompres serai hangat. Pengukuran intensitas nyeri menggunakan skala numerik 0-10. Analisa data secara univariat dan bivariate dengan $t$ - test dependent.

\section{HASIL DAN PEMBAHASAN}

\section{Analisis univariat}

\section{Karakteristik Responden Berdasarkan}

1. Jenis Umur

Tabel 1. Distribusi Frekuensi responden Berasarkan Umur Lansia PSTW

\begin{tabular}{llll}
\hline No & Kategori Umur & Jumlah & \multicolumn{1}{c}{$\%$} \\
\hline 1 & Middle Age & 2 & 13.3 \\
2 & Elderly & 10 & 66.7 \\
3 & Old & 3 & 220.0 \\
Total & 15 & 100 \\
\hline
\end{tabular}

(Sumber : Data Primer, 2018)

Tabel 1 menunjukkan dari 15 responden, mayoritas $10(66,7 \%)$ kategori Eldery yaitu 65-75 tahun. Lanjut Usia ( Eldery) cenderung mengalami penurunan aktifitas karena terjadinya penurunan fungsi tubuh akibat proses penuaan. 


\section{Jenis Kelamin}

Tabel 2. Distribusi Frekuensi Responden Berdasarkan Jenis Kelamin

\begin{tabular}{cccc}
\hline \multirow{2}{*}{ No } & $\begin{array}{c}\text { Jenis } \\
\text { Kelamin }\end{array}$ & Jumlah & $\%$ \\
\hline 1 & Laki-laki & 7 & 46.7 \\
2 & Perempuan & 8 & 53.3 \\
& Total & 15 & 100 \\
\hline
\end{tabular}

(Sumber : Data Primer, 2018)

Dari tabel 2 menunjukkan bahwa jenis kelamin terbanyak yang menderita Arthritis reumatoid adalah perempuan yaitu 8 (53,3\%). Perbedaan jenis kelamin telah diidentifikasi dalam hal nyeri dan respon nyeri dimana laki laki kurang mengekspresikan nyeri yang dirasakan secara berlebihan dibandngan dengan wanita (Potter and Perry, 2005). Berdasarkan penelitian terdahulu yang dilakukan Andriani (2016) didapatkan bahwa dari 20 lansia, mayoritaslansia perempuan yaitu sebesar $65 \%$ dan laki laki sebesar $35 \%$.

\section{Gambaran Skala Nyeri Arthrtitis} Rheumatoid Sebelum dan Sesudah Diberikan Kompres Serai Hangat Tabel 3 .Gambaran Skala Nyeri Sebelum dan Sesudah diberikan Kompres Serai Hangat

\begin{tabular}{ccc}
\hline No & $\begin{array}{c}\text { Sebelum } \\
\text { Diberikan } \\
\text { Kompres Serai }\end{array}$ & $\begin{array}{c}\text { Sesudah } \\
\text { Diberikan } \\
\text { Kompres Serai }\end{array}$ \\
\hline 1 & 8 & 6 \\
2 & 6 & 3 \\
3 & 5 & 3 \\
4 & 7 & 5 \\
5 & 7 & 3 \\
6 & 8 & 6 \\
7 & 8 & 7 \\
8 & 8 & 5 \\
9 & 6 & 4 \\
10 & 7 & 4 \\
11 & 6 & 3 \\
12 & 7 & 3 \\
13 & 7 & 4 \\
14 & 6 & 2 \\
15 & 8 & 4 \\
\hline Jumlah & 104 & 62 \\
\hline Rata-rata & 6,90 & 4,13 \\
\hline
\end{tabular}

Berdasarkan analisa tabel 3 dapat disimpulkan rata-rata intensitas nyeri responden sebelum diberikan kompres hangat dengan nilai rata-rata 6,90 (Nyeri sedang -berat). Dapat disimpulkan sebelum pemberian kompres serai hangat, responden mengalami Nyeri berat $(66,7 \%)$ dan Nyeri sedang sebanyak (33,3\%). Adapun skala nyeri Arthrtitis Rheumatoid responden sesudah diberikan kompres serai hangat dengan rata rata 4,13 (nyeri ringansedang). Kesimpulannya setelah pemberian kompres hangat ada satu (1) responden masih mengalami nyeri berat $(6,7 \%)$,dan yang mengalami pengurangan nyeri sedang $(53,3 \%)$ dan nyeri ringan sebanyak $(40 \%)$.

Nyeri merupakan suatu fenomena yang kompleks. Nyeri merupakan suatu mekanisme pertahanan tubuh manusia yang dapat mengindikasikan bahwa tubuh seorang mengalami masalah. Nyeri dapat berasal dari fisik atau psikologis (Tamher \& Heryati, 2008 ). Merasakan nyeri pada lanjut usia dapat mempengaruhi aktifitas fisiknya sehari hari, hal ini karena beberapa faktor yang mempengaruhinya diantaranya umur, jenis kelamin, budaya , perhatian, kecemasan, pengalaman sebelumnya, dukungan keluarga dan sosial, dan keletihan.

Nyeri yang dirasakan seseorang juga bersifat subyektifitas dan masing masing orang dapat berbeda beda meskipun kasusnya sama, sehingga perawat perlu untuk melakukan pendekatan yang berbeda pula.

Tanaman serei mengandung minyak atsiri yang memiliki sifat kimiawi dan efek farmakologi yaitu rasa pedas dan bersifat hangat sebagai anti radang (anti inflamasi) dan menghilangkan rasa sakit atau nyeri yang bersifat analgetik serta melancarkan sirkulasi darah, yang di indikasikan untuk menghilangkan nyeri otot dan nyeri sendi pada penderita artritis rheumatoid, badan pengalinu dan sakit kepala (Hembing, 2007) . 
Pemberian kompres serai hangat adalah memberikan rasa hangat pada bagian tertentu seperti sendi, kai dan tagan responden dengan menggunakan cairan serai bertujuan melancarkan peredaran darah,mengurangi rasa sakit, mmberi rasa nyaman dan ketenangan.

\section{Analisa bivariat}

\begin{tabular}{|c|c|c|c|c|}
\hline \multicolumn{5}{|c|}{$\begin{array}{l}\text { Pengaruh Kompres Serai Hangat } \\
\text { Terhadap Intensitas Nyeri Arthrtitis } \\
\text { Rheumatoid } \\
\text { Tabel 4. Pengaruh Pemberian Kompres } \\
\text { Serai Hangat Terhadap Intensitas Nyeri } \\
\text { Arthrtitis Rheumatoid lansia }\end{array}$} \\
\hline Variabel & Mean & $\begin{array}{c}\text { Standar } \\
\text { Deviasi }\end{array}$ & $\begin{array}{l}\text { Std. } \\
\text { Eror }\end{array}$ & $\begin{array}{c}P \\
\text { Value } \\
\end{array}$ \\
\hline $\begin{array}{lr}\text { Skala nyeri } \\
\text { sesudah di } \\
\text { berikan } \\
\text { kompres serai }\end{array}$ & 6,86 & 1.060 & . 273 & 0.000 \\
\hline $\begin{array}{lr}\text { Skala nyeri } \\
\text { sesudah } \\
\text { berikan }\end{array}$ & 4,13 & & & \\
\hline
\end{tabular}

Dari tabel di atas diketahui bahwa skala nyeri Arthrtitis Rheumatoid responden sebelum dan sesudah diberikan kompres serai hangat, dimana rata-rata sebelum diberikan kompres serai adalah 6,86 dengan standar deviasi 1.060 dan standar eror 0,273 sedangkan sesudah diberikan kompres hangat serai rata-rata skala nyeri Arthrtitis Rheumatoid adalah 4,13 dengan standar deviasi 1.407 dan standar eror 0,363 . Hasil uji statistik paired t-test didapatkan nilai $p$-value $=0,000<$ 0,05 dengan selisih nilai mean 2,73. Dapat disimpulkan ada Pengaruh pemberian kompres serai hangat terhadap penurunan Intensitas nyeri Arthrtitis Rheumatoid pada lansia.

LeMone (2017), menjelaskan nyeri sendi merupakan keluhan utama yang sering dirasakan setiap penderita arthtritis rheumatoid. Intensitas nyeri pada seseorang dapat dirasakan berbeda-beda antara individu dengan individu lainnya. Hal-hal yang membuat nyeri berkurang adalah seperti olahraga, istirahat, nafas dalam, penggunaan obat maupun non farmakologis. Penanganan penderita Arthrtitis Rheumatoid difokuskan pada cara mengontrol rasa sakit yaitu nyeri, penanganan dapat meliputi terapi non farmakologi seperti kompres serai.

Nyeri kronis yang berlanjut dapat menyebabkan seseorang menarik diri dari hubungan social dan menjadi tidak aktif secara fisik (Rosdahl, 2017). Salah satu cara yang dapat dilakukan untuk mengurangi rasa nyeri yaitu dengan kompres serai. Kompres serai hangat sangat mudah untuk dilakukan karena hanya merebus daun serai setelah itu air rebusan hangat hangat kuku, dan kompreskan ketempat yang nyeri dengan menggunakan handuk. Selain itu kompres ini juga praktis dilakukan karena tanpa banyak mengeluarkan biaya dan aman digunakan. Kompres ini dilakukan selama 15 menit. Kandungan dalam serai adalah astiri yang dapat menghilangkan rasa sakit, nyeri, dan anti peradangan.

Hal ini sesuai dengan penelitian Andriani,(2016) yang berjudul " pengaruh kompres serei hangat terhadap penurunan intensitas Nyeri artritis rheumatoid pada lanjut usia". Hasil yang diperoleh didapatkan perbedaan intensitas nyeri artritis rheumatoid sebelum dan setelah dilakukan kompres serei hangat.

Penelitian ini juga sejaan dengan penelitian Sarah (2019) berjudul "Pengaruh Kompres Serei Hangat terhadap Intensitas Nyeri Arthritis Rheumatoid pada Lanjut usia di Panti Jompo Graaha Residen Senior Medan " dengan hasil ada perbedaan nilai nilai rata rata nyeri Arthritis Rheumatoid pada responden sebelum dan sesudah intervensi dengan kompres serei hangat yaitu 1,391 dimana nilai thitung lebih besar dari t tabel $(13,37)$, probabilitas $(\mathrm{p}=0,000)$ atau $\mathrm{p}<0,05$, sehingga disimpulkan kompres serai hangat yang diteliti mempunyai pengaruh terhadap pnurunan intensitas nyeri arthritis rheumatoid pada lanjut usia. 
Menurut asumsi peneliti, dengan memberikan intervensi kompres serei hangat pada responden yang menderita Arthritis Rheumatoid, terlihat terjadi penurunan intensitas nyerinya, ini dikarenakan dalam tanaman serei terkandung suatu enzim, yaitu enzim siklooksigenase yang dapat mengurangi peradangan yang diserap melalui kulit pada daerah yang meradang/ bengkak, selain itu serei juga memiliki efek farmokologis yaitu rasa pedas yang bersifat hangat, efek hangat ini akan meransang sistem effektor sehingga mengeluarkan signal yang akan mengakibatkan terjadinya vasodilatasi perifer. Perubahan ukuran pembuluh darah diatur oleh pusat vasomotor pada Medulla Oblongata dari tangkai otak, dibawah pengaruh hipotalamik bagian anterior sehingga terjadi vasodilatasi.Terjadinya vasodilatasi ini menyebabkan aliran darah ke setiap jaringan khususnya yang mengalami radang dan nyeri bertambah, sehingga terjadi penurunan nyeri sendi pada jaringan yang meradang. Oleh sebab itu kompres serai perlu diberikan pada pasien yang mengalami nyeri khususnya penderita Arthrtitis Rheumatoid sebagai salah satu intervensi terapi nyeri non farmakologi yang aman.

\section{SIMPULAN}

Berdasarkan hasil penelitian ini dapat disimpulkan terjadi penurunan intensitas nyeri Arthrtitis Rheumatoid pada lansia setelah diberikan kompres serai hangat. . Ada pengaruh pemberian kompres serai hangat terhadap intensitas nyeri Arthritis Rheumatoid pada lansia di PSTW Kota Jambi.

Harapannya hasil penelitian ini dapat digunakan oleh masyarakat dan khususnya tenaga kesehatan untuk mensosialisasikan dan memberikan pendidikan kesehatan tentang terapi ini yang bertujuan untuk mengurangi nyeri sendi ataupun peradangan lainnya terutama bagi lansia sebagai terapi non farmakologi.

\section{DAFTAR PUSTAKA}

Andriyani M, 2016, Pengaruh Kompres Serei Hangat Terhadap Penurunan Intensitas Nyeri Artritis Rheumatoid Pada Lanjut Usia, Jurnal Ipteks Terapan, diakses Bulan Juni 2019.

Azizah. 2011. Tanda dan Gejala Masa Penuaan. Jakarta

Bandiyah, Siti. 2009. Lanjut Usia dan Keperawatan Gerontik. Nuha Medika. Yogyakarta

C.Zahroh, Faiza .2018. Pengaruh Kompres Hangat Terhadap Penurunan Nyeri Penderita Penyakit Artitis Gout. Jurnal Ners dan Kebidanan http://jnk.phb.ac.id/index.php/jnk .

Chairuddin. 2003. Nanda Nic-Noc Aplikasi Asuhan Keperawatan Berdasarkan Diagnosa Medis. Jakarta ; EGC

Corwin E, J. 2009 Buku Saku Patofisiologi. EGC. Jakarta

Dalimartha, S. 2008. Herbal Untuk Pengobatan Reumatik. Penebar Swadaya. Jakarta.

DepkesRI. 2006. Proses Penunaan Pada Lansia.

Dinas Kesehatan Provinsi Jambi. 2017. Jumlah Lansia beserta Penyakit Sendi di Provinsi Jambi. Dinkes Provinsi Jambi. Jambi

Hamidi. 2004. Khasiat dan Manfaat Serai. Jakarta

Hembing, W. 2007. Atasi Asam Urat dan Rematik Ala Hembing. Jakarta : PuspaSwara

Hidayat. A. A. 2009. Metode Penelitian Keperawatan Dan Teknik Analisis Data. Selemba Medika. Jakarta.

Hidayat, A. A. 2017. Metodologi Penelitian Keperawatan dan Kesehatan. Salemba Medika. Jakarta.

Infodatin lansia. 2016. Situasi Lanjut Usia (Lansia) di Indonesia. Pusat Data dan Informasi Kementrian Kesehatan RI. Jakarta. 
Isamas. 2013. Hasil Riset Kesehatan Arthritis Rheumatoid.

Iskandar. 2008. Manajemen Non Farmakologi Arthtritis Rheumatoid.

Judha, Muhammad, dkk. 2012. Manajemen Nyeri. Salemba Medika : Jakarta

Kemenkes RI. 2017. Analisis Lansia di Indonesia. Kementrian Kesehatan RI. Jakarta.

Kozier \& Erb. 2008. Fundamental Keperawatan Konsep, Proses dan Praktik. EGC. Jakarta.

Maryam, K. 2008. Mengenal Usia Lanjut. Salemba Medika, Jakarta.

Notoatmodjo, S. 2005. Metodologi Penelitian Kesehatan. Rineka Cipta. Jakarta.

Nursalam 2011. Konsep Dan Penerapan Metodologi Penelitian Ilmu Keperawatan : Pedoman Skripsi, Tesis, Dan Instrumen Penelitian Keperawatan. Selemba Medika. Jakarta.

Padila. 2013. Buku Ajar Keperawatan Gerontik. Numed. Yogyakarta.

Potter \& Perry. 2005. Fundamental Keperawatan. EGC. Jakarta

PSTW Budi Luhur Jambi. 2018. Jumlah Lansia beserta Penyakit di Panti Sosial Tresna Werdha Budi Luhur Jambi Tahun 2015-2018. PSTW Budi luhur Jambi. Jambi.

Purwaningsih. 2009. Keperawatan Gerontik. Jakarta :FKUI

Purwoastuti, Th Endang. 2009. Waspadai Gangguan Rematik. Kanisius. Yogyakarta.

Riskesdas. 2018. Hasil Riset Kesehatan Dasar Kementrian Kesehatan RI. http://www.depkes.go.id/resources/do wnload/general/Hasil\%20Riskesdas\% 202018.pdf. Diakses 10 Agustus 2018.

Romadlani. 2010. Kompres Hangat Serai Pada Pasien Arthritis Rheumatoid.

Sarah,M. 2019. Pengaruh Kompres Serei Hangat Terhadap Intensitas Nyeri Artritis Rheumatoid pada lanjut Usia
DiPanti jompo Graha Residen Senior Karya Kasih Medan.Jurnal Mutiara Ners,238-243(e-journal.sari-

mutiara.ac.id) Downloads/863Article\%20Text-3165-2-10-

20191120\%20(1).pdf. diakses 6April 2020

Setiawati. 2007. Manfaat Tanaman Obat Keluarga. Jakarta: EGC.

Sugiono. 2008. Statistika Untuk Penelitian. Bandung: Alfabeta

Wiarto, Giri. 2017. Nyeri Tulang dan Sendi. Gosyen Publishing. Yogyakarta 